\title{
MINERALOGY AND TECHNOLOGICAL PROPERTIES OF SOME KAOLIN TYPES USED IN THE CERAMIC INDUSTRY
}

\author{
MARCEL BENEA ${ }^{1} \&$ MARIA GOREA ${ }^{2}$
}

\begin{abstract}
Three different kaolin types used in ceramic industry were analyzed by different methods in order to obtain a complete mineralogical and technological characterisation. Studies were carried out by using a combination of analyses (XRD, SEM, methylene blue absorption, particle size distribution) of both the bulk sample, and the fine fraction. The main technological characteristics (drying and firing shrinkage, Pfefferkorn plasticity index, rheology, resistance, and colour after firing) of the ceramic masses prepared by using the analyzed kaolin types were also established. As a result, a direct relationship between the mineralogical composition and particle size distribution of different kaolin types vs. the technological properties of the raw and fired ceramic products was evidenced.
\end{abstract}

Keywords: Kaolin, ceramic industry, technological characteristics.

\section{INTRODUCTION}

Kaolin is used for various purposes and the required grade depends on the use. Despite the fact that the paper industry is the major consumer of kaolin (as filler), most often it is used as a traditional raw material in the ceramic industry (i.e. production of whiteware). Kaolin is also used as filler in the production of rubber, plastics and pigments, in the refractory materials, cosmetics, pharmaceutical, food industries, and also for the production of synthetic zeolites.

The mineralogy and the technological properties of any clay materials are the main features that are investigated in order to find out the best solution to use them in the ceramic industry.

This study presents the influence of the mineralogical composition and particle size distribution of three different kaolin types (KO1 and MK2 from Ukraine and respectively $\mathrm{BOJ}$ from Bulgaria) on the main technological features.

For this purpose, the main technological characteristics (i.e. drying and firing shrinkage, Pfefferkorn plasticity index, rheology, resistance, and colour after firing) of the ceramic masses prepared by using the analyzed kaolin types were established. As a result, a direct relationship between the mineralogical composition and particle size distribution of different kaolin types vs. the technological properties of the raw and fired ceramic products was noticed.

\section{ANALYTICAL METHODS}

The XRD patterns $\left(2-70^{\circ} 2 \theta\right)$ were obtained by using a Philips PW 1710 diffractometer equipped with Bragg-Brentano geometry, Cu-anticathode $(45 \mathrm{kV}, 40$ $\mathrm{mA}$ ), and graphite monochromator. Following a well-established pre-treatment

\footnotetext{
1 "Babeş-Bolyai" University, Department of Mineralogy, Kogălniceanu 1, 400084 Cluj, Romania (e-mail: mbenea@bioge.ubbcluj.ro)

2 "Babeş-Bolyai" University, Department of Chemistry, Arany lanos, 11, 400028 Cluj, Romania
} 
methodology (use of chemicals, ultrasonic treatment, dispersion procedures, clay mineral concentration by centrifugation and sedimentation, oriented and random powder preparation, cation saturation, expansion/dehydration methods), a number of 12 X-ray diffraction (XRD) patterns were obtained from each sample. Scanning electron microscopy (SEM), using a Philips XL30 ESEM, was also used in order to illustrate the morphology of the identified mineral phases. For a better characterization, the cation exchange capacity (CEC) and surface area (SA) were also measured by absorption of methylene blue method. The particle size distribution was obtained by using a laser granulometer of a FRITSCH-ANALYSETTE 22-type.

\section{RESULTS AND DISCUSSION}

The interpretation of the XRD patterns of the bulk samples (Fig. 1), and of the fine clay fraction $(<2 \mu \mathrm{m})$ (Fig. 2$)$ led to the identification of the following mineral phases: kaolinite, illite, quartz, and in only one sample, also vermiculite (Table 1).

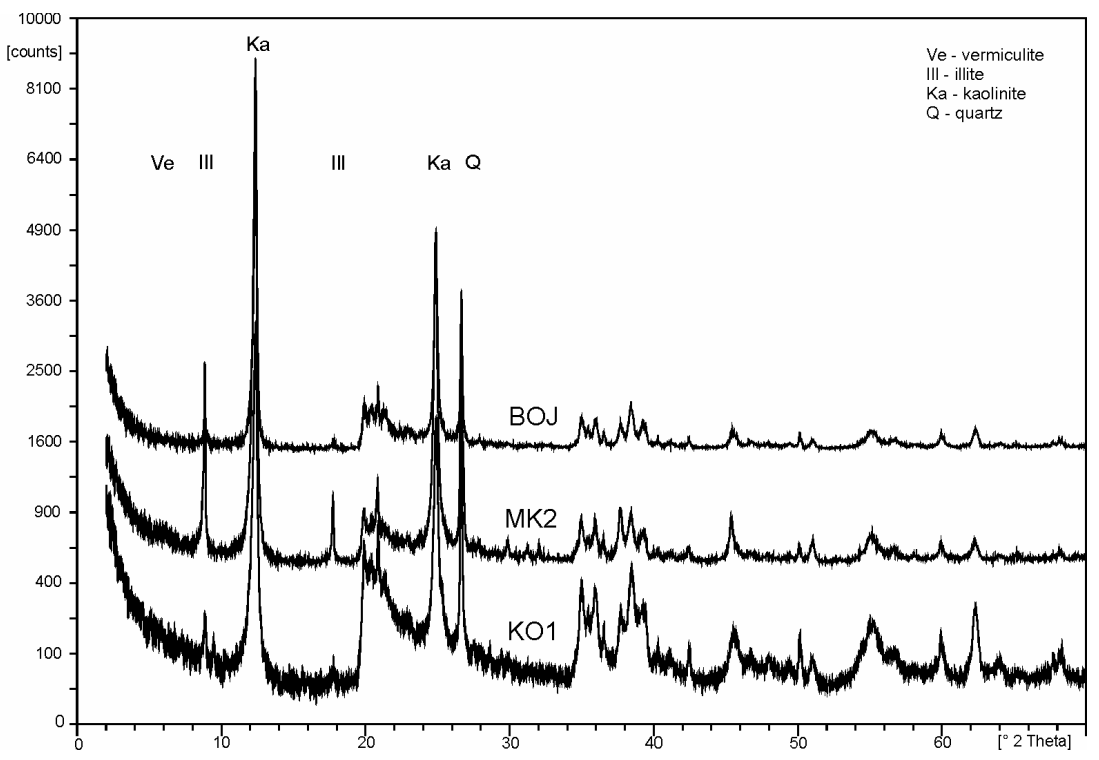

Fig. 1. X-ray diffraction patterns of bulk samples.

The semiquantitative mineralogical composition was determined based on relative peak intensities (mostly of lower orders) and peak areas corrected by various factors (Riedmüller, 1978; Tributh, 1991).

Despite the fact that the Hinckley crystallinity index is not widely used because it is influenced by the presence of quartz, feldspar, iron oxides and other clay minerals, it remains an empirical estimate of the kaolinite degree of crystallinity. The Hinckley crystallinity index was obtained by measuring the heights of the $(1 \overline{1})$ and $(11 \overline{1})$ kaolinite peaks in the region between 15 and $30^{\circ}(2 \theta)$. The obtained values 
show that BOJ-type kaolin contains the best-crystallized kaolinite crystals (Table 1). Some of the SEM images of the analyzed kaolin samples are presented in Figs. 5, 6 , and 7 .

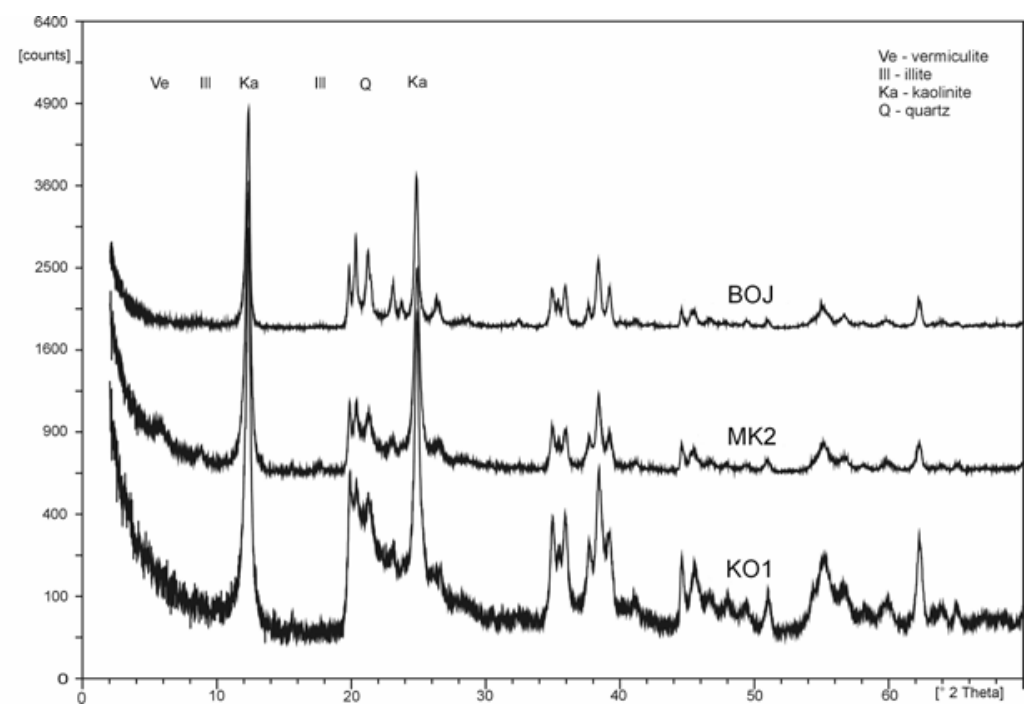

Fig. 2. X-ray diffraction patterns of the $<2 \mu \mathrm{m}$ fraction.

Table 1

Semiquantitative mineralogical composition [wt. \%].

\begin{tabular}{lccc}
\hline \multirow{2}{*}{ Mineral } & \multicolumn{3}{c}{ Kaolin type / sample number } \\
\cline { 2 - 4 } & KO1 / 4810 & MK2 / 4811 & BOJ / 4812 \\
\hline Kaolinite & 89.00 & 69.85 & 82.95 \\
Illite & 6.00 & 19.50 & 10.40 \\
Quartz & 5.00 & 7.65 & 6.65 \\
Vermiculite & - & 3.00 & - \\
\hline Hinckley index & 0.44 & 0.87 & 1.35 \\
\hline
\end{tabular}

The presence of the well-crystallized kaolinite is also suggested by the (060) reflections at $62.31^{\circ} 2 \theta(1.49 \AA)$ (Table 2 and Fig. 3), and the transformation in metakaolinite after thermal treatment at $550^{\circ} \mathrm{C}$. The SEM images (Figs. 5, 6, and 7) complete the diagnosis.

Table 2

Values of $d(060)$ and ${ }^{\circ} 2 \theta$ for the main identified mineral phases.

\begin{tabular}{lcc}
\hline Mineral & $d(060)$ & ${ }^{\circ} 2 \theta$ \\
\hline Kaolinite & 1.490 & 62.31 \\
& 1.499 & $(62.224-62.292)$ \\
\hline Illite & 1.541 & 61.90 \\
\hline \multirow{2}{*}{ Vermiculite } & $(59.914-603$ \\
\end{tabular}


The particle size distributions of the analyzed kaolin samples are presented in Table 3 and Fig. 4. The MK2-type is characterized by relatively larger sizes of the particles - the fraction between 5 and $60 \mu \mathrm{m}$ represents $79.37 \%$ and the fraction below $5 \mu \mathrm{m}$ represents $19.02 \%$. In KO1-type, $61.86 \%$ are particles below $5 \mu \mathrm{m}$, while in BOJ-type $53.05 \%$ are below $5 \mu \mathrm{m}$.

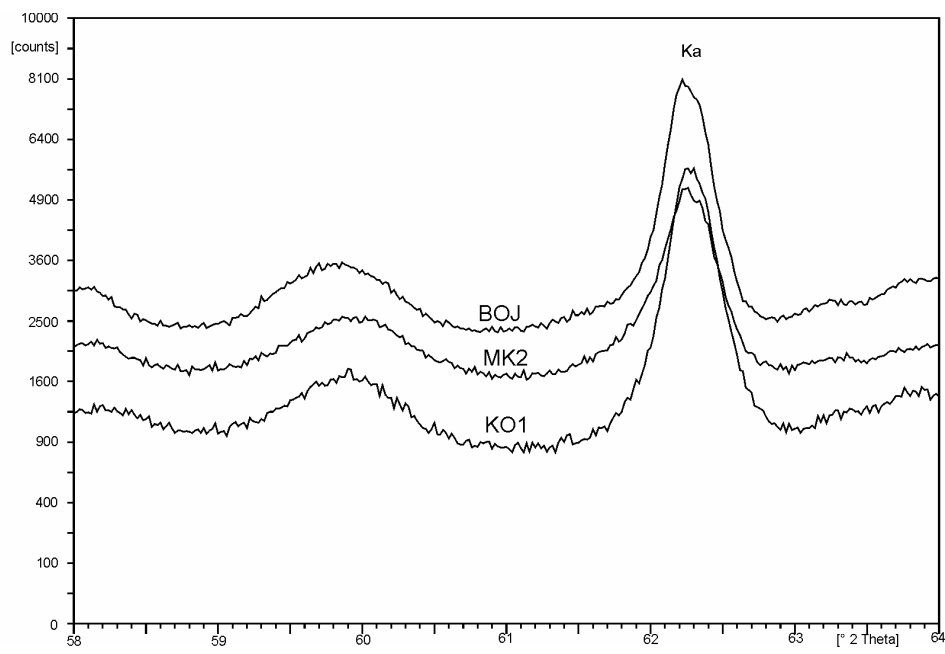

Fig. 3. X-ray diffraction patterns of the $<2 \mu \mathrm{m}$ fraction using long count times and small scale factor; the presence of kaolinite $(\mathrm{Ka})$ is obvious.

Table 3

Particle size distributions of the analyzed kaolin samples.

\begin{tabular}{cccc}
\hline \multirow{2}{*}{ Sample } & \multicolumn{3}{c}{ Particle size [\%] } \\
\cline { 2 - 4 } & $<0.005 \mathrm{~mm}$ & $0.005-0.060 \mathrm{~mm}$ & $>0.060 \mathrm{~mm}$ \\
\hline KO1 / 4810 & 61.86 & 38.14 & 0.00 \\
MK2 / 4811 & 19.02 & 79.37 & 1.61 \\
BOJ / 4812 & 53.05 & 47.95 & 0.00
\end{tabular}

Cation exchange capacity (CEC) and surface area (SA) were measured by using the titration method, respectively the absorption of methylene blue. The obtained values (Table 4) are relatively similar and comparable with those from the literature.

Table 4

Cation exchange capacity (CEC) and surface area (SA).

\begin{tabular}{lccc}
\hline \multirow{2}{*}{ Parameter } & \multicolumn{3}{c}{ Kaolin type / sample number } \\
\cline { 2 - 4 } & $\mathrm{KO} 1 / 4810$ & $\mathrm{MK} 2 / 4811$ & $\mathrm{BOJ} / 4812$ \\
\hline CEC $[\mathrm{mequ} / 100 \mathrm{~g}]$ & 36.10 & 31.30 & 36.70 \\
$\mathrm{SA}\left[\mathrm{m}^{2} / \mathrm{g}\right]$ & 310 & 269 & 316 \\
\hline
\end{tabular}


The chemical composition of kaolin is important because of its influence on the behavior of ceramic masses during the thermal treatment; an $\mathrm{Al}_{2} \mathrm{O}_{3}$ content higher than $30 \%$ is necessary for increasing the refractory and mechanical resistance. Table 5 presents the chemical composition of the analyzed kaolin samples.

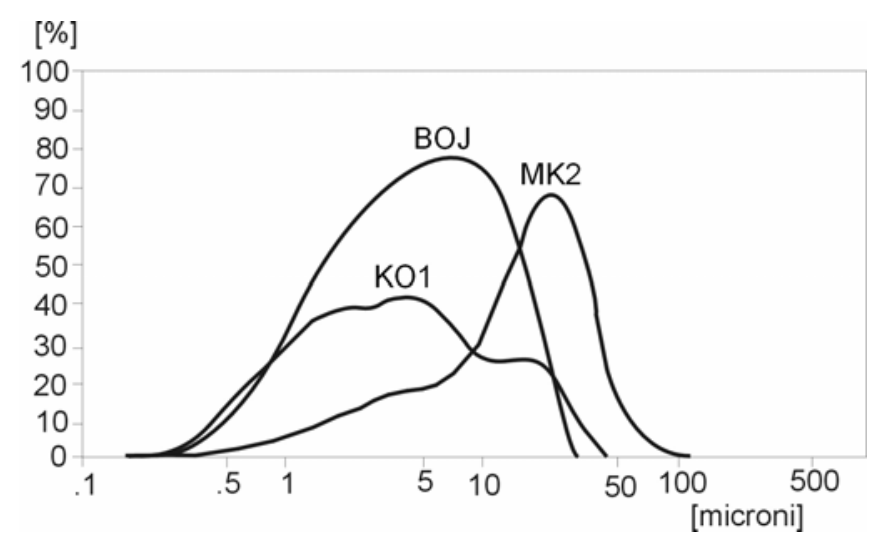

Fig. 4. Particle size distribution diagrams of the studied kaolin samples.

Chemical composition of the analyzed samples.

Table 5

\begin{tabular}{c|c|c|c|c|c|c|c|c}
\hline $\begin{array}{c}\text { Oxide/ } \\
\text { Sample }\end{array}$ & $\mathrm{SiO}_{2}$ & $\mathrm{Al}_{2} \mathrm{O}_{3}$ & $\mathrm{TiO}_{2}$ & $\mathrm{Fe}_{2} \mathrm{O}_{3}$ & $\mathrm{CaO}$ & $\mathrm{MgO}$ & $\mathrm{K}_{2} \mathrm{O}$ & L.O.I. \\
\hline $\mathrm{KO} 1$ & 44.54 & 37.81 & 1.39 & 0.87 & 0.30 & 0.22 & 0.18 & 14.70 \\
$\mathrm{MK} 2$ & 49.29 & 34.84 & 0.41 & 1.11 & 0.40 & 0.45 & 1.76 & 11.75 \\
$\mathrm{BOJ}$ & 49.55 & 35.38 & 0.41 & 0.90 & 0.24 & 0.32 & 1.06 & 12.15 \\
\hline
\end{tabular}

The chemical compositions of MK2 and BOJ samples are very similar but the technological characteristics (Table 6) differ due to the mineralogical composition and particle size distribution.

The presence of kaolinite with high crystallinity index in sample BOJ determines a good rheology and a low drying shrinkage of the kaolin. A low content of kaolinite with lower crystallinity index and the presence of vermiculite and illite imprint a weak rheological behaviour and a higher drying shrinkage of sample MK2. The low firing shrinkage of this sample due to the particle size distribution can be noted.

Table 6

Technological characteristics of the studied kaolins.

\begin{tabular}{l|c|c|c}
\hline \multirow{2}{*}{ Characteristics / Kaolin type } & \multicolumn{3}{c}{ Kaolin type } \\
\cline { 2 - 4 } & KO1 & MK2 & BOJ \\
\hline Pfefferkorn plasticity index [\%] & 39.30 & 36.00 & 39.10 \\
Drying shrinkage [\%] & 7.00 & 7.04 & 6.80 \\
Firing shrinkage [\%] & 10.34 & 5.23 & 11.47 \\
Drying resistance [kgf/cm $\left.{ }^{2}\right]$ & 16.50 & 17.00 & 18.00 \\
Rheology & medium & weak & good \\
Color after firing & white & white & cream white \\
\hline
\end{tabular}


MARCEL BENEA, MARIA GOREA

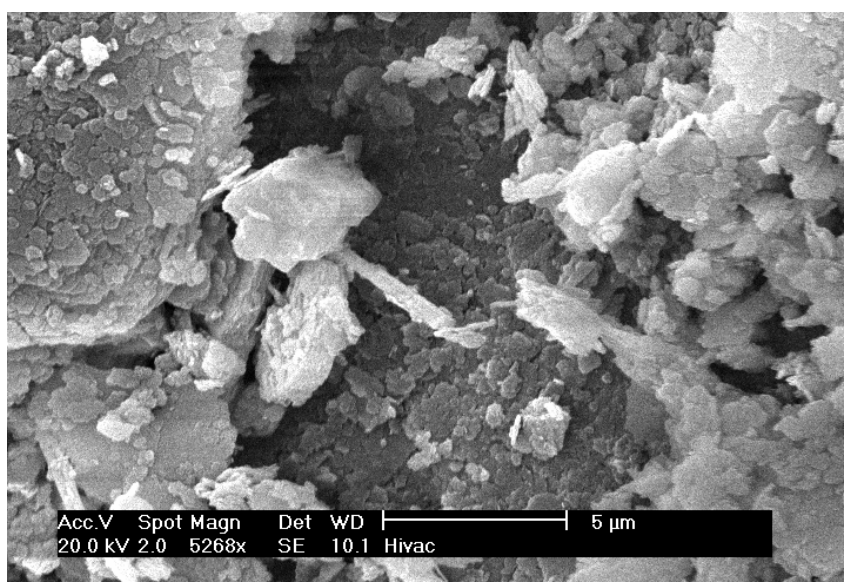

Fig. 5. Sample KO1 - kaolinite crystals.

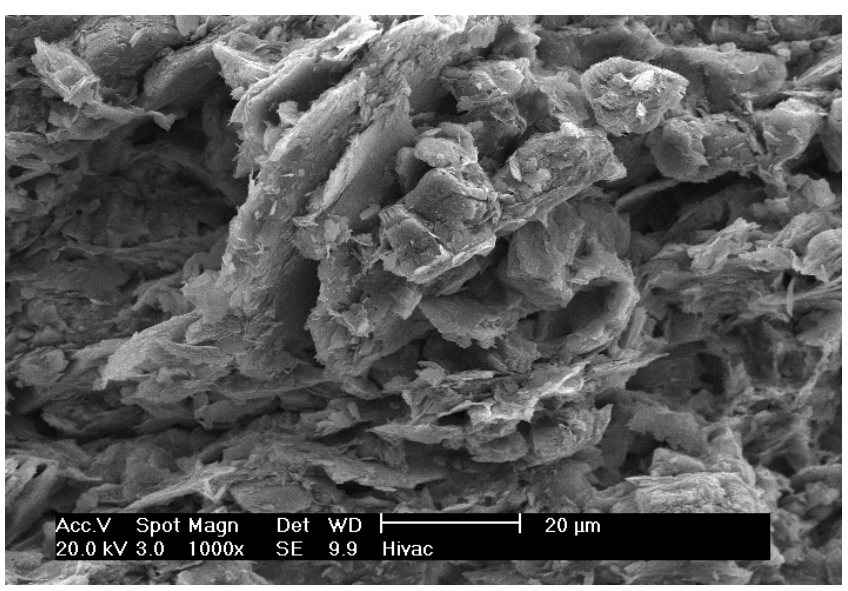

Fig. 6. Sample MK2 - kaolinite crystals.

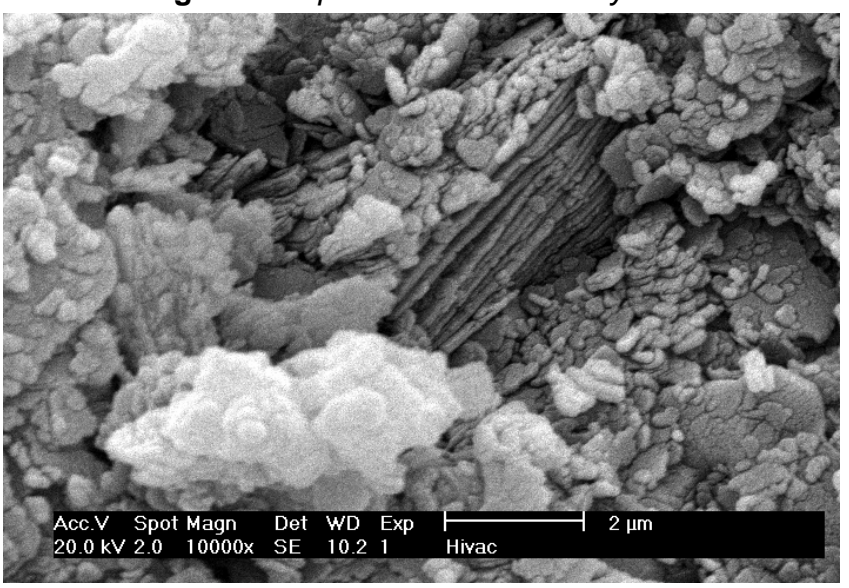

Fig. 7. Sample BOJ - kaolinite crystals. 


\section{CONCLUSIONS}

The MK2-type, vermiculite - containing kaolin shows a weak rheology, the lowest value of the cation exchange capacity (CEC) and accordingly of the surface area (SA); this is due to a relatively higher amount of quartz and to a particle size distribution characterized by larger sizes of the particles - the fraction below $5 \mu \mathrm{m}$ represents only $19.02 \%$.

In the case of KO1-and BOJ - kaolin types, the technological characteristics and the CEC and SA values are almost identical, as a consequence of the similar mineral compositions and particle size distributions: $61.86 \%$ in sample KO1, and $53.05 \%$ in sample BOJ are particles below $0.5 \mu \mathrm{m}$, respectively.

As a conclusion regarding the technological characteristics (high plasticity and drying resistance, low drying shrinkage and good rheology), the BOJ kaolin type is the most suitable raw material for ceramic casting bodies.

Acknowledgements. The authors highly appreciate the technical support provided by the Institut für Angewandte Geologie (Universität für Bodenkultur) Wien and S.C. Faimar S. A. Baia Mare.

\section{REFERENCES}

Riedmüller, G. 1978, Neoformations and transformations of clay minerals in tectonic shear zones. TMPM Tschermaks Min. Petr. Mitt. 25, pp. 219-242.

Tributh, H. 1991, Qualitative und quantitative Bestimmung der Tonminerale in Bodentonen. In: Identifizierung und Charakterisierung von Tonmineralen (Tributh, H. \& Lagaly, G., Eds.). Beiträge zur Jahrestagung der DTTG, Giessen, pp. 37-85. 